\title{
ANALISE DE REDES DE PROTEÇÃO SOCIAL NA CIDADE DE CURITIBA: VISUALIZAÇÃO CARTOGRÁFICA COMO ESTRATÉGIA METODOLOGICA
}

\author{
Analysis of social networks protection at \\ curitiba: cartographic visualization as a \\ methodological approach \\ Samira Kauchakje* \\ Luciene Stamato Delazari**
}

\section{Resumo}

Esse artigo apresenta os resultados preliminares da pesquisa sobre a rede de proteção social em Curitiba-PR. O objetivo é discutir estratégias metodológicas para identificar e analisar a rede e para tal, tem-se a junção de conhecimentos de redes sociais com os conhecimentos técnico-científicos da área de cartografia.

Palavras-chave: Rede social. Visualização cartográfica. proteção social.

* Docente do PPGTU, da Pontifícia Universidade Católica do Paraná; mestrado e doutorado em Educação pela UNICAMP. Email: samira.kauchakje@pucpr.br

** Docente do Departamento de Geomática da UFPR; mestrado em Ciências Geodésicas pela UFPR; doutorado em Engenharia pela USP. Email: luciene@ufpr.br 


\section{Abstract}

This article presents the first results of a research about social networks in the city of Curitiba. The objective is to discuss methodological strategies to identify and analyze the network. In this sense, the knowledge of cartography is merged to knowledge of social networks

Keywords: Social network. Rights. Social protection.

\section{INTRODUÇÃO}

Este artigo apresenta uma discussão sobre as estratégias metodológicas adotada na pesquisa sobre Rede de Direitos e Proteção Social nas Cidades $^{1}$. Esta pesquisa tem por objetivo analisar a configuração da rede de proteção social - seus agentes organizacionais, projetos e inter-relações - em Curitiba. A estratégia adotada tem como centralidade a representação gráfica das redes sociais e sua análise cartográfica.

Atualmente, as representações gráficas têm sido utilizadas em diferentes áreas para possibilitar a proposição de soluções para problemas que envolvem a componente espacial. Às tradicionais aplicações dos mapas, somam-se outras pouco exploradas, ou até mesmo não imaginadas. Como exemplos podem-se citar o mapeamento de informações sociais, relativas ao funcionamento de entidades e instituições sociais (DELAZARI, 2004) e a construção de um portal com informações sobre a rede socio-assistencial no Estado do Paraná (DELAZARI et al, 2005).

Assim, a construção de representações gráficas das redes sociais permitirá subsidiar as análises espaciais de maneira a compreender a formação, as interações e 0 impacto de uma rede social na democratização da cidade e na transformação das condições de vida urbana. Para tal faz-se necessário compreender quais são as análises realizadas pelos especialistas em Redes Sociais com a utilização de grafos para conhecer os atributos das redes, bem como de cada um de seus componentes, hierarquias e posições na malha de articulação; e como os especialistas propõem ações sobre as redes sociais, considerando suas características a partir destas análises. 
Este trabalho apresenta a aplicação do conhecimento técnicocientífico da Cartografia na representação de redes sociais, visando a soluções de representações espaciais para subsidiar a análise das redes e seus relacionamentos. De modo a subsidiar tais análises, são apresentadas, como exemplo, algumas representações da rede de direitos à segurança alimentar no município de Curitiba.

\section{PROTEÇÃO SOCIAL E REDE DE DIREITOS}

O campo social e política da proteção social possui uma dinâmica interna em que comparece tanto a interação entre os atores como tensões e conflituoso. Esta dinâmica desencadeia proposições de ações sociais, conquistas, ampliações e regressões históricas para a proteção social dos membros de sociedades e em seu entendimento como direito e pacto civil.

Neste campo comparecem diferentes agentes sociais, com também diversas posições ideológicas e políticas: pessoas envoltas em laços de pertencimento e que conformam a solidariedade primária (familiares, vizinhança, compadrio, entre outros); organizações e grupos sociais cuja base é a solidariedade comunitária e humanitária (por exemplo: igrejas, organizações não-governamentais de caráter filantrópico e ou confessional, voluntariado); organizações movimentalistas (como os movimentos sociais, fóruns e organizações não-governamentais articuladas aos mesmos) caracterizados pela vocalização das demandas por garantias e seguranças sociais para a instituição de relações políticas solidárias e; Estado cuja legitimidade permite transitar por grupos de interesse e conflitos, forjando uma solidariedade político-contratual.

Pode-se considerar que nos marcos históricos dos sistemas protetivos nas sociedades ocidentais há o entrelaçamento conflitivo entre tais agentes e suas perspectivas valorativas: Tradicionalmente a proteção social aos membros da sociedade considerados mais vulneráveis ou em situação de desvantagem social era prestada por meio dos laços de pertencimento primário, denominados de laços de solidariedade horizontal. Na Idade Média a proteção assentada nas relações de pertencimento ocorria em conjunto com a caridade ofertada pela Igreja Católica (CASTEL, 1998). Nos séculos XVIII e XIX, a revolução burguesa-liberal (que faz emergir o 
Estado de Direito) conjugada às lutas sociais de cariz socialista promovem a passagem gradual da proteção social para a responsabilidade do Estado. A proteção é considerada menos como ajuda ou benesse e mais como direito, especialmente, entre a primeira metade do século XX até os anos 1980, formatando o Estado de Bem-Estar Social. Após os anos 1970, o campo ideológico e a reestruturação econômica, favoráveis a políticas liberais acarretam a (re) privatização da responsabilidade quanto questão social e, com isso, sérios agravos em termos de direitos sociais de grupos sociais e populações inteiras, seja pelas destituições materiais e empobrecimento, seja por discriminação étnica ou de gênero, por exemplo (FLEURY, 1994). Entretanto, na atualidade, ao mesmo tempo em que há fortes retrocessos em termos de civilidade, identificam-se potencialidades de uma robusta trama interativa de solidariedade politizada, ou melhor, de relações políticas solidárias, com implementação de projetos e intervenções sócioeconômicas e culturais na esfera local, regional, nacional e planetária (SCHERERWARREN, 2006; TOURAINE, 2006; KAUCHAKJE, 2005; AVRITZER \& NAVARRO, 2003). Esta última tendência possibilitaria a constituição de uma rede de direitos.

A literatura e as pesquisas sobre gestão pública municipal, sobretudo a partir dos anos 1980, têm buscado demonstrar novas configurações de agentes sociais como alternativas para (re) construção de identidades cívicas influindo sobre formas de governança. Nesta esteira encontram-se os debates de diferentes tons ideológicos e teóricos sobre governança social negociada (HIRST, 2000); experimentos participativos na gestão pública (AVRITZER e NAVARRO, 2003); estilos de gestão pública, com ênfase na gestão em rede (FREY, 1996); ampliação do número de pessoas e organizações políticas e sociais envolvidos na formulação e implementação de políticas e de planejamento urbano (PIERRE 2000; KICKERT. et al, 1999) e; sobre novas formas de governança urbana, baseadas no princípio da organização em rede (COHEN, 2006). Tais arranjos de gestão têm sido interpretados como condições de acesso de setores da sociedade civil no âmbito da administração pública, não apenas como demandatários, mas como sujeitos nas discussões e deliberações que definem o interesse público e a agenda pública. 
Especialmente as organizações não-governamentais - ONGs têm sido compreendidas como forma de enfrentamento do novo desenho internacional, que alinha o processo de mundialização financeira à localização da questão social gerada globalmente - pobreza, discriminação étnicocultural, preconceito de gênero, precarização do trabalho, violação dos direitos humanos e problemas sócio - ambientais - apresentando projetos de desenvolvimento social. Entretanto este universo não é homogêneo e as características que uma gestão ou projeto social, realizado em conjunto com estas organizações, adquire, se relaciona com as características das próprias ONGs envolvidas. Neste sentido as ONGs podem se classificadas de acordo com os seguintes tipos: movimentalistas - no geral têm relações com movimentos sociais, mas também, podem estar articuladas a setores de partidos políticos, igrejas e empresas cujos propósitos sóciopolíticos vão em direção à democratização social e política; filantrópicas - associações que têm missão e motivação humanitária para a ajuda e proteção aos considerados necessitados e carentes. Podem ser laicas ou confessionais; confessionais - associações que atuam orientadas por princípios religiosos, em especial da caridade, numa relação estreita com igrejas e; empresaria - associações vinculadas às ações de responsabilidade social empresarial, que no geral, atuam em projetos de cunho humanitário e em ações socioambientais.

Assim, numa rede de proteção social existem impactos contraditórios decorrentes da parceria público-privado, representada pela relação entre Estado e ONGs: por um lado a desresponsabilização do Estado quanto ao investimento de recursos financeiros, políticos, humanos e legais em políticas e programas sociais; por outro, 0 aprofundamento da sensibilidade social e da solidariedade comunitária; além de haver a possibilidade de fortalecimento de agentes sociais motivados pelo horizonte da construção de uma nova sociabilidade assentada na justiça social (KAUCHAKJE, 2002).

A análise da rede de proteção social deve considerar a diferença entre:

a) projetos e atividades sociais sob responsabilidade principal do Estado (mesmo que compartilhada e com o controle da sociedade 
civil organizada) que, tendencialmente se inserem no código cultural e normativo-legal da solidariedade política que transita na esfera dos direitos de cidadania; e,

b) ações sociais de responsabilidade dos setores organizados da sociedade civil que podem se misturam com códigos da solidariedade humanitária privada que transita na esfera da caridade e da ajuda, trazendo o risco de que direitos sejam (re) transfigurados em benesses.

Para esta análise uma estratégia é combinar diferentes recursos de representação e categorização tais como os apresentados a seguir.

\section{COLETA DE DADOS E REPRESENTAÇÃO GRÁFICA DA REDE DE PROTEÇÃO SOCIAL NA CIDADE.}

Para a identificação da rede de agentes sociais a pesquisa adaptou os procedimentos metodológicos desenvolvidos por Kauchakje; Penna; Frey e Duarte (2006), que centra a coleta de dados em sítios da Internet. Considerase que na $W E B$ os agentes sociais se articulam em redes temáticas, por identidade e para realização de projetos, também se referenciam em links. Estas inter-relações têm as seguintes características:

- Parceria temática: constituída pelos atores que expressam certa constância de propósitos declarados, tanto em termos de missão/tema das ações quanto de objetivos. Estes atores, porém, não precisam necessariamente compartilhar valores, ideários, concepções políticas, causas ou projetos sociais, mas têm suas atividades direcionadas para a mesma temática ou política.

- Parceria identitária: atuação no mesmo campo temático com compartilhamento de valores, ideários, concepções políticas, causas sociais e ou projetos societários. Sugere laços fortes de longa duração e permanência de articulação.

- Parceria em projeto: expressa cooperação mútua em programas, projetos, ações e iniciativas conjuntas, ações coordenadas entre atores que estão sendo concretamente desenvolvidas nas cidades pesquisadas. Os parceiros em projeto, ao menos durante o seu desenvolvimento, costumam ser parceiros temáticos, mas não 
necessariamente identitário (conforme entendimento mencionado anteriormente). No caso dos patrocinadores/apoiadores de projetos, esta parceria pode ser temporalmente limitada à duração do projeto ou das ações desenvolvidas. Sugere a existência de laços entre os agentes sociais, que podem ser fortes ou fracos, permanentes ou temporárias, que se estabelecem, no mínimo, durante o desenvolvimento da ação/ projeto enunciado.

- Parcerias de apoio e colaboração: são relações organizações sociais em que as inter-relações se baseiam na disponibilização de recursos financeiros ou de outra espécie.

- Hyperlinks de referência: apresentam relações de referência sobre o campo de interesse, valores e universo temático das organizações entre si.

De acordo com os autores citados a proposta metodológica possui dois momentos entrelaçados e distintos: os procedimentos de coleta e representação dos dados e informações e os procedimentos de análise, subdivididos nos seguintes itens:

a) seleção da temática no âmbito dos direitos sociais com o recorte territorial;

b) busca na Internet de organizações sociais referentes à temática;

c) definição dos atores mais significativos;

d) reconhecimento em cada sítio dos atores de ações e projetos comuns, articulações temáticas e identitárias e apoios-colaboradores locais (técnica Bola de Neve) (KAUCHAKJE et al. 2006);

e) representação da rede identificada em grafos e mapas (DELAZARI; KAUCHAKJE; PENNA, 2005);

f) análise a partir dos pontos de partida teóricos que permitem a atribuição de seu significado pelo pesquisador.

Para o caso da pesquisa sobre a rede de proteção social que está 
sendo desenvolvida e é objeto de discussão deste artigo, o momento da análise contará com os mapas temáticos. Isso porque, como foi visto, uma rede de proteção social possui dinâmicas e conflitos nas cooperações estabelecidas que se desenvolvem em localizações geográficas. A particularidade destas localizações pode sugerir sentidos e esclarecer a dinâmica das redes. Por isso, a visualização cartográfica será empregada para gerar as representações que darão subsídio às análises.

\section{VISUALIZAÇÃO CARTOGRÁFICA E ANÁLISE DE REDES SOCIAIS}

A partir da década de 60 e após anos de desenvolvimento de ferramentas computacionais para Cartografia Digital, cujo propósito foi automatizar os processos convencionais para produção de mapas, principalmente de cartas topográficas, ocorre no início dos anos 90 uma mudança no âmbito da Cartografia Digital. Esta mudança significa entender que os mapas não são apenas ferramentas para comunicação de conhecimento espacial, mas sim ferramentas para aquisição de novos conhecimentos sobre o comportamento espacial dos fenômenos, uma vez que é possível ao usuário interagir ativamente no processo de visualização dos fenômenos representados (SLUTER, 2001 a; SLUTER, 2001b). Os mapas são então utilizados tanto para exploração dos dados, visando à aquisição de conhecimento sobre uma determinada realidade, como para apresentar resultados alcançados, comunicar resultados. Este processo é denominado visualização cartográfica.

A ênfase da visualização cartográfica está mais em seu poder exploratório do que em aspectos comunicativos; está direcionada para o descobrimento e entendimento dos fenômenos espaciais. As pesquisas atuais em cartografia tendem a buscar a integração das ferramentas computacionais aos produtos cartográficos, para gerar visualizações que atendam às fases de exploração e análise de dados.

Dentro deste contexto, surge a idéia de representar espacialmente as redes sociais. Redes sociais são compreendidas como pessoas, grupos e instituições, chamados de nós, que se interligam. A noção é de que o conjunto das relações num sistema social pode ser representado por uma rede, por exemplo, por meio de um conjunto de pontos interligados total ou parcialmente. 


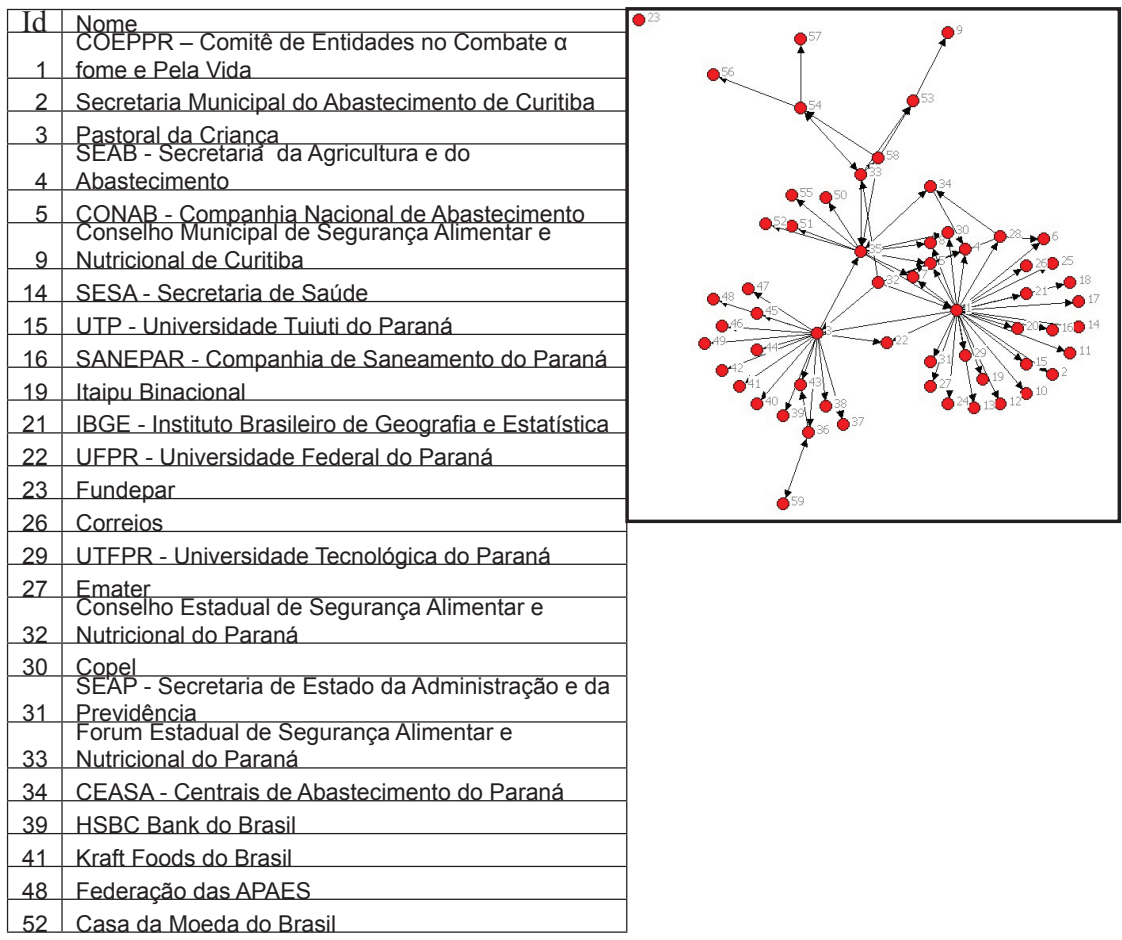

Fig. 1 - Representação da rede social de Segurança Alimentar em Curitiba, gerada pelo programa UCINET e a respectiva lista de atores

Normalmente, os analistas de redes sociais utilizam duas formas para representar a informação sobre padrões das relações entre os atores de uma rede: grafos e matrizes. O grafo consiste de pontos (nós) para representar os atores e arcos para representar as relações ou ligações. Estes grafos podem ser chamados de sociogramas. A figura 1, extraída dos resultados da pesquisa, apresenta um grafo gerado pelo programa UCINET (http://www. analytictech.com/), com a respectiva tabela de atores ${ }^{2}$.

O programa UCINET é um software para análise de dados sobre redes sociais, que inclui as medidas de centralidade, identificação de subgrupos, regras de análise, entre outras possibilidades. Além disso, apresenta 
rotinas para análise de matrizes, tais como álgebra matricial e estatística multivariada.

A maior diferença entre dados convencionais e dados de redes é que os dados convencionais possuem foco nos atores e atributos, enquanto que os dados de redes possuem foco nos atores e suas relações. As análises de redes enfatizam as relações entre os atores, o que significa que estes normalmente não são amostrados independentemente, como no caso de outros tipos de dados.

As representações sob a forma de grafos apresentam dois problemas: (1) as localizações espaciais dos nós da rede não são representadas e

(2) as soluções gráficas não são definidas de maneira a representar os atributos dos componentes dos grafos. Estes problemas necessitam de solução, pois:

a) a representação das localizações espaciais é necessária para as análises de conhecimento sobre as relações de proximidade e vizinhança. A representação dos atributos (características) dos componentes dos grafos é necessária para as análises de agrupamentos e dispersões, tendências, regiões de influências, entre outras.

b) as localizações espaciais permitem conhecer fluxos em termos de regiões de influência culturais, políticas e econômicas na dinâmica das articulações das redes sociais.

Segundo Rodrigues e Mustaro (2006), para o estudo e análise de redes, a teoria dos grafos é muito útil, pois os atores são os vértices e os laços sociais são as arestas, sendo que estas arestas podem ser orientadas ou não dependendo da reciprocidade dos laços entre os atores. Como nem sempre as relações entre os atores são recíprocas, pode-se utilizar grafos orientados para a representação das redes.

Um conceito importante para avaliação das redes é o de centralidade. Segundo Marteleto (2001), calcular a centralidade de um ator significa identificar a posição em que ele se encontra em relação à trocas e à comunicação na rede. Quanto mais central é um indivíduo, mais bem posicionado está em relação às trocas e à comunicação, o que aumenta o seu poder na rede.

As medidas de centralidade podem ser divididas em três tipos (Marteleto, 2001): da informação, de proximidade e de intermediação. Na 
centralidade da informação um indivíduo é central em relação à informação quando, por seu posicionamento, recebe informações vindas da maior parte do ambiente da rede. A centralidade de proximidade está relacionada ao menor caminho que o ator precisa percorrer para alcançar os outros elos da rede, ou seja, quanto menor este caminho, mais central é o indivíduo. Por fim, a centralidade de intermediação consiste no potencial daqueles que servem de intermediários; calcula o quanto um ator facilita o fluxo de informação de uma determinada rede.

\section{Projeto cartográfico para a representação das redes sociais}

A primeira etapa da realização de um projeto cartográfico é o entendimento das necessidades do usuário, que permite identificar como os especialistas em redes sociais utilizam os grafos e as tabelas, e quais são as análises que precisam realizar. Esta etapa consistiu de entrevistas com os usuários, e da utilização dos grafos gerados com o programa UCINET, quando foi possível identificar as seguintes análises a serem conduzidas sobre as redes:

a) A visualização das localizações espaciais dos atores e suas ligações. Os grafos apresentam a rede como um aglomerado sem relações de proximidade ou vizinhança entre os atores. Com os mapas o usuário poderá analisar esta distribuição.

b) A concentração de atores em determinadas regiões, o que permitirá verificar e entender porque algumas regiões são melhor assistidas do que outras. Além disso, será possível planejar a instalação de novos atores em locais sem assistência social.

c) O tipo de atores para cada região, o que permitirá analisar quais regiões são atendidas por organizações governamentais ou nãogovernamentais.

d) As ligações entre os atores considerando sua localização espacial. Isso permitirá visualizar as ligações e distâncias.

e) A representação das ligações entre atores considerando as diferentes esferas de governo: municipal, estadual ou federal. 
f) As centralidades que permitirão visualizar quais atores são mais significantes e influentes.

Conhecidas as análises realizadas pelos usuários, é possível definir as informações a serem representadas nos grafos, bem como seus significados e características. O conhecimento das características das informações analisadas permite sua sistematização e a definição dos critérios para a classificação destas informações. Nesta fase é possível, então, estabelecer as escalas de análise e discriminar quais mapas serão gerados. Para cada mapa, as soluções gráficas são definidas a partir dos princípios de linguagem cartográfica. São definidas as escalas e as dimensionalidades da representação.

Considerando que a rede de proteção social em Curitiba foi definida tendo por base seis direitos - Educação, Trabalho, Assistência Social, Saúde, Segurança Alimentar e Habitação - para cada um será construído um conjunto de representações sobre as articulações das organizações sociais envolvidas em sua implementação (rede de direitos à proteção social). Inicialmente as representações apresentam as características dos agentes sociais/atores em suas localizações específicas. Para o Município de Curitiba são apresentadas a divisas de Regionais, divisas de bairros, e as localizações dos atores, com suas respectivas classificações. Como exemplo tem-se as seguintes situações:

a) Representação do tipo de organização juntamente com o tipo de enlace. $\mathrm{Na}$ figura 2 é apresentada a legenda que será utilizada para representar estas informações.

b) As organizações não-governamentais são classificadas em filantrópicas, filantrópicas confessionais, empresariais, relacionadas ao Estado ${ }^{3}$ e movimentalistas, conforme a figura 2 .

c) A representação da centralidade, sendo que para cada setor devem ser geradas 3 representações (centralidade em grau, de informação e de intermediação). A figura 3 apresenta a centralidade de informação, a título de exemplo.

d) A representação das ligações entre os atores e tipos de organizações, como apresentadas na figura 4 . 


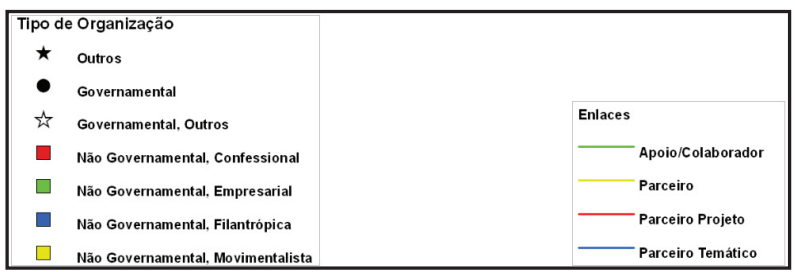

Fig. 2 - Legenda da tipologia das organizações (governamentais e nãogovernamentais) e dos enlaces

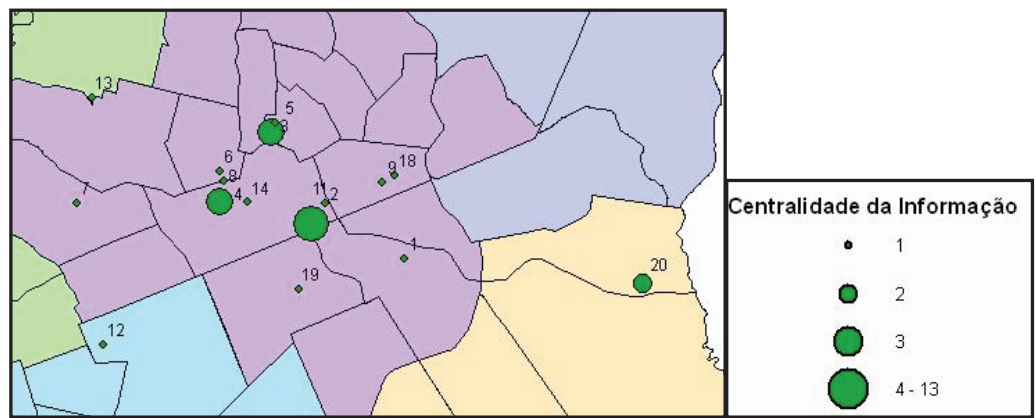

Fig. 3 - Centralidade da informação para o direito à segurança alimentar em Curitiba

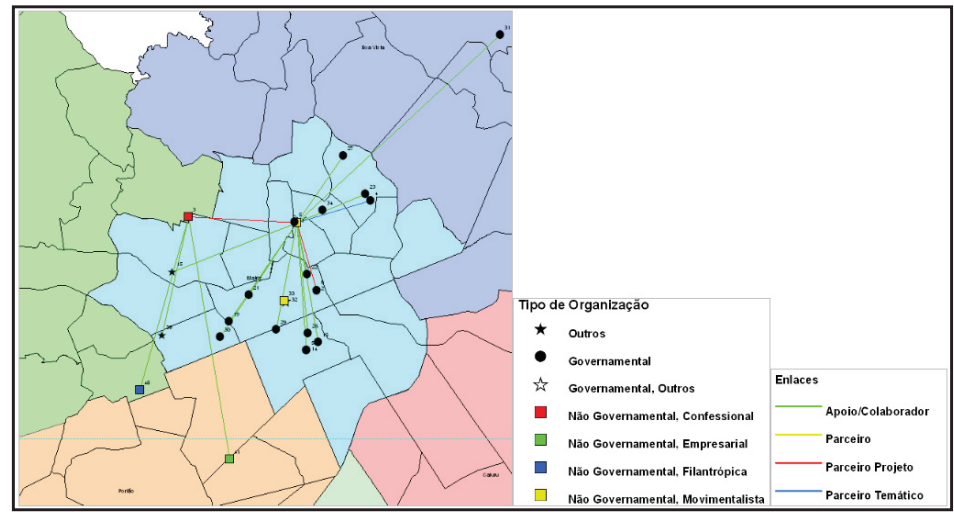

Fig. 4 - Tipologia dos atores e suas ligações para o direito à segurança alimentar em Curitiba 


\section{ANÁLISE DE REDE SOCIAL: ALGUMAS POSSIBILIDADES SUBSIDIADAS PELA VISUALIZAÇÃO CARTOGRÁFICA}

A visualização da localização das organizações espaciais permite imediatamente refletir sobre os dados referentes ao tipo de organização predominante em cada localidade bem como ao tipo de enlace. Com isto pode-se buscar conhecer as características e especificidades espaciais (neste caso as divisões regionais e bairros curitibanos) para estabelecer relações analíticas e explicativas sobre predominância, em certos lugares, de organizações de caráter movimentalista ou filantrópico ou acerto sobre parceria temáticas ou para elaboração de projetos, por exemplo.

Num movimento dialético, a representação da rede nos mapas temáticos pode possibilitar a apreensão da possível influência da configuração cultural e sócio-econômica da localidade sobre as características das organizações ali presentes, e também, o impacto destas organizações sobre a configuração do espaço. Isto é particularmente importante para o caso de uma rede de proteção social que, esperase, atua privilegiadamente em espaços de exclusão, com prioridade para a articulação realizada (enlaces) para o desenvolvimento de projetos sociais.

É claro que a sede de uma organização pode estar localizada próxima ou não de onde são desenvolvidas as ações, o que é uma das características da rede objeto da investigação. Mas esta é outra informação que os mapas temáticos auxiliam na análise pela própria visualização, isto é, reconhecer os países ou bairros e regiões administrativas de Curitiba, sedes de organizações, que estão mais presentes nas ações protetivas na cidade, e ensaiar explicações sobre isto. Os tipos de enlaces e de Ongs localizados espacialmente podem indicar uma espécie de divisão de trabalho internacional e local, e mesmo a maior capacidade de coordenar e concentrar recursos e meios (financeiros e humanos, em especial) para a realização ou apoio a ações sociais. ${ }^{4}$

Em síntese, considera-se que o espaço não é apenas um continente das ações e de localização das organizações, mas que suas especificidades fazem diferença nas características que uma rede social possa adquirir, da mesma forma que a rede pode influir na configuração do espaço. 


\section{CONSIDERAÇÕES FINAIS}

Empreender esforços metodológicos para analisar as redes socais é relevante, sobretudo na atualidade, quando os sistemas de proteção social consolidados entre 1940-1970 perderam sua base legitimadora, associadas às condições concretas (econômicas e políticas) para a continuidade de sua implementação. Essa perda, entretanto, não significou, até o momento, a inexistência deste sistema nos paises que o construíram, de variadas formas, mas sim uma exigência de outra configuração.

A metodologia adotada pode fornecer pistas sobre as características potenciais da proteção social na atualidade, em sociedades que arquitetaram este sistema no passado, e têm que considerar esta obra nos processos decisórios que $o$ têm modificado no presente.

Isto por duas razões: primeiro, porque se pode partir do pressuposto que um sistema de proteção social (no campo da transferência redistributiva de renda e de acessos aos recursos e patrimônios materiais e culturais, por meio de políticas sociais e econômicas) foi elaborado por um tipo de Estado entendido como esfera autônoma que implementa ações a partir de seus recursos de poder, e, sendo assim, mesmo permeado por mobilizações e interesses de grupos sociais e classes fundamentais da sociedade, não é seu refém. Ainda mais: este tipo de Estado representa um avanço civilizatório mediado pela reformatação do Estado de Direito como Estado Social. Isto posto, admite-se que, nas sociedades ocidentais advindas da modernidade, o processo em curso de deslegitimação e corrosão das condições concretas de incremento do sistema protetivo pode trazer, como uma das tendências, uma forma (ainda que não um retorno) de relações sociais com frágil ou ausente regulamentação social, interventiva, de Estado. Neste caso, e somente neste caso de considerar como admissíveis o pressuposto e a tendência apresentados, então, uma das características potenciais do campo da proteção social seria a de regressão civilizatória.

Portanto, a visualização cartográfica, como estratégia metodologica para subsidiar a análise de rede sóciotécnica de proteção social, está relacionada com a noção de espaço adotada, ou seja, de que o espaço não consiste apenas dos lugares sociais de realização das ações institucionais, da presença do Estado e de organizações não-governamentais, mas 
também o espaço do mundo da vida, no qual se concretizam as relações de construção da existência física, econômica, cultural e social e suas respectivas representações. Como diz Balsa (2006, p. 15), "em última análise, considera-se que o espaço só existe através das representações dos indivíduos, os quais são considerados capazes de orientar a forma como se realiza a própria apropriação do espaço”. Esta noção incorpora também a sugestão teórica de Milton Santos (1997) de que espaço é um conjunto indissociável de sistemas de objetos e sistemas de ação.

\section{REFERÊNCIAS}

AVRITZER, L.; NAVARRO, Z. (orgs.). A inovação democrática. São Paulo: Cortez, 2003.

BALSA, Casemiro (org.). Relações sociais de Espaço. Lisboa: Colibri, CEOS, 2006.

CASTEL, Robert. As metamorfoses da questão social: uma crônica do salário. Petrópolis: Vozes, 1998.

COHEN, T. T. Egler. Contribuición metodológica para la investigación de redes tecnosociales. Pre-til. Bogota, n.12, 2006.

DELAZARI, L. S. Modelagem e implementação de um Atlas Eletrônico Interativo utilizando métodos de visualização cartográfica. Tese de doutorado apresentada e defendida no Departamento de engenharia de Transportes, USP. Outubro, 2004.

DELAZARI, L. S; KAUCHAKJE, S; PENNA, M. C. Sistema de Informação Geográfica da Política de Assistência Social do Paraná. Anais do XXII Congresso Brasileiro de Cartografia, 2005, Macaé, 2005. v. 1.

FLEURY, S. Estado sem cidadãos: seguridade social na América Latina. Rio de Janeiro: FIOCRUZ, 1994.

FREY, K. (1996) Crise do Estado e estilos de gestão municipal. São Paulo: Lua Nova, n.37.

GOHN, M.da G. Conselhos Gestores e participação sociopolitica. São Paulo;Cortez, 2001 . 
HIRST, P. (). Democracy and governance. In: Jon Pierre (ed.): Debating governance: authority, steering and democracy. Oxford University Press: New York. 2000.

KAUCHAKJE, S. (2005). Alternatives pour recomposer lês liens sociaux et la civilité dans lês rapports sociétaires au Brésil. Res Socialis. Fribourg Suisse, vol. 24.

KAUCHAKJE, S.; PENNA, M.C.; FREY, K; DUARTE, F. Redes socio-técnicas y participación ciudadana: propuestas conceptuales y analíticas para el uso de las TIC's. In; Redes- Revista hispana para el análisis de redes sociales. Vol.11, 3, Diciembre 2006. Disponível em: < http://revista-redes.rediris.es > . Acesso em: 10/01/2006.

KICKERT, W. et al. (1999). Managing complex networks: strategies for the public sector. London: Sage.

MARTELETO, R. M. Análise de redes sociais - aplicação nos estudos de transferência da informação. Ciência da Informação, v.30, n.1 , jan./abr. 2001. p.71-81.

PIERRE, J. (org.). (2000). Debating governance: authority, steering and democracy. New York: Oxford University Press.

RODRIGUES, L. C.; MUSTARO, P. N. Levantamento de características referentes à análise de redes sociais nas comunidades virtuais brasileiras de jogos on-line. Universidade Presbiteriana Mackenzie - São Paulo - Departamento de Ciência da Computação. 2006. < <ttp:/www.sbc.org.br/bibliotecadigital/download.php?paper $=560>$ Acesso em: 18 abr 2007.

SANTOS, M. A natureza do espaço: técnica e tempo, razão e emoção. São Paulo: Hucitec, 1997

SCHERER-WARREN, I. (2006). Das mobilizações às redes de movimentos sociais. Sociedade e Estado. Dossiê Movimentos sociais. Brasília, v. 21, n.1.

SLUTER, Claudia Robbi. Sistemas Especialistas para Geração de Mapas Temáticos. Revista Brasileira de Cartografia, Curitiba, v. 53, 2001 a.

SLUTER, Claudia Robbi. Visualização Cartográfica: o Avanço da Cartografia Digital e Pesquisas Futuras. In: XX CONGRESSO BRASILEIRO DE CARTOGRAFIA, 2001, Porto Alegre. O Espaço Sem Fronteiras. Porto Alegre: Mundo Virtual, $2001 \mathrm{~b}$.

TOURAINE, A. (2006). Na fronteira dos movimentos sociais. Sociedade e Estado. Dossiê Movimentos sociais. Brasília, v. 21, n.1. 